\title{
Oriental Lacquer III. Composition of the Urushiol Fraction of the Sap of Rhus verniciflua ${ }^{\dagger}$
}

\author{
Jan Bartus, William J. Simonsick, Jr., ${ }^{*}$ Charles Garner, ${ }^{* *}$ \\ Takafumi NishiURA, ${ }^{* * *}$ Tatsuki Kitayama, ${ }^{* * *}$ \\ Koichi Hatada, ${ }^{* * *}$ and Otto VogL \\ Polytechnic University, Six MetroTech Center, Brooklyn, New York, N.Y. 11201, U.S.A. \\ * Marshall R\& D Laboratory, E.I. Du Pont de Nemours \& Co., \\ Philadelphia, PA 19146, U.S.A. \\ ** Department of Chemistry, Baylor University, Waco, TX 76798-7348, U.S.A. \\ *** Department of Chemistry, Faculty of Engineering Science, Osaka University, \\ Toyonaka, 'Osaka 560, Japan
}

(Received May 26, 1993)

\begin{abstract}
The urushi fraction of several samples of the sap of Rhus verniciflua was analyzed by a combination of capillary gas chromatography, supercritical fluid chromatography, high resolution NMR spectroscopy and two techniques of mass spectrometry. The composition of the urushi fraction of these samples was found to consist in general of the components that had been found by former analyses of urushi samples. Some new understanding of the components recognized gives a more accurate recognition of the ingredients of oriental lacquers.

KEY WORDS Urushi / Japanese Lacquer Tree / Rhus verniciflua / Analysis of Urushiol / Gas Chromatography / NMR Spectroscopy / Mass Sepctrometry /
\end{abstract}

Oriental lacquer is a clear sap, obtained by tapping lacquer trees in the same way as natural rubber is harvested from rubber trees. High quality Japanese lacquerware uses specially prepared urushi samples for the coating of cedar wood as the foundation because cedar wood will not warp or shrink. The lacquer is applied in as many as 30 layers. The Japanese lacquer contains several ingredients in addition of the urushiol base depending on the desired effects and on the coloring. As the final layer, a clear lacquer is applied and the piece of lacquerware is then polished and takes on a brilliant luster. The lacquer of oriental lacquerware is a crosslinked polymer and is resistent to water, alcohol, and oils. ${ }^{1-5}$

The Japanese lacquer tree Rhus verniciflua is the common source for Japanese lacquer. The skin of lacquer trees grown for several years is removed, the trunk is cut, and the sap that exudes is collected. The sap is a water/oil emulsion, and the "oily" portion consists of about $60-65 \%$ of urushiol. The sap also consists of about $20-25 \%$ of water and about

* The correct name for the 'varnish tree' or the Japanese lacquer tree is Toxicodendron vernicifluum (Stokes) F. Barkeley. The names Rhus verniciflua Stokes, a name used in ref 2, 3, and 5 and Rhus vernicifera D.C. ${ }^{1,4}$ are synonyms. [The New Royal Horticultural Society Dictionary of Gardening, Vol. 4, A. Huxley, M. Griffiths, and M. Levy, Ed., Stockton Press, New York, N.Y., 1992, p 489-490; see also C. Benezra, G. Ducombs, Y. Sell, and J. Fousserean, "Plant Contact Dematitis," B.C. Decker Inc., Philadelphia, 1985, p 80].

The family Anacardiaceae consists of about 600 species. Particularly well known are those members which produce poisonous sap. The temperate genus Toxicondron has been the subject of numerous studies. Virtually all of the Anacardiaceous oleoresins that induce contact dermatitis are mixtures of phenolic compounds [John D. Mitchell, Advances in Economic Botany, 8, 103 (1990)]. 
$10 \%$ of water soluble plant gums, mono-, oligo-, and polysaccharides and small amounts of enzymes such as stellacyanin and peroxidase, but most importantly, the enzyme laccase. The quality of a given raw urushi depends mainly on the amount of the content of the urushi triene component, of the amount, and of the activity of the oxidation enzyme laccase.

To prepare the lacquer sap for the actual coating material, the sap is stirred in an open vessel at room temperature for about one and a half hour, and then at a temperature increasing from 20 to $45^{\circ} \mathrm{C}$ for two to four hours until the water content is reduced to $2-4 \%$ ("sugurome" process). The temperature cycle must be carefully controlled to retain the activity of the enzymes. ${ }^{2}$ At this point the sap has become clear, has changed in color, and has increased in viscosity. The resultant liquid, known as "raw lacquer", consists of urushiol and oligo-urushiol, small amounts of water, small amounts of other ingredients, and is ready for application. Sometimes the unprocessed sap is used as the base coat of the substrate and the "raw lacquer" for the top coat.

The lacquer is now coated onto the substrate, dried for one day at $20-25^{\circ} \mathrm{C}$ and at relative humidity of $60-80 \%$. The curing of the urushiol is caused by oxidation of the urushiol and the other ingredients of the raw lacquer by the enzymes present in the sap. Laccase is the most important enzyme for the polymerization of usushiol. It is a copper-glycoprotein enzyme, has a highly specific activity, and causes the oxidation of ortho and para-dihydroxybenzene derivatives, the active components of urushiol. The mechanism of urushiol curing has been studied and the oxidative dimerization of the urushiol compounds was extensively investigated. ${ }^{5-13}$

Up to the present time, a number of techniques have been used for the analysis and characterization of the ingredients of urushiol. They include various separation techniques like high performance liquid chromatography (HPLC), and also gas chromatography (GC).
From the point of view of characterization it should be noted that the sap of the lacquer tree is a mixture of components with distinctively different molecular weight (degree of unsaturation and geometric isomers of the olefinic groups of the hydrocarbon side chain of the urushiol components) and polarity.

Urushi from Rhus verniciflua consists of about $80 \%$ of a mixture of catechol derivatives substituted in 3-position with $\mathrm{C}_{15}$ hydrocarbon carbon chains; about $70 \%$ are trienes and $20 \%$ are monoenes with some dienes also present. The composition of the urushiol may vary depending on growing conditions of the Rhus vericiflua tree and on the season. ${ }^{2}$

It was our objective to evaluate additional techniques and combinations of techniques for the analysis of the urushiol fraction and the identification of its individual components. We were particularly interested in using potassium ionization of desorbed species $\left(\mathrm{K}^{+}\right.$IDS) mass spectrometry for the characterization of the components of urushiol. We also attempted to combine this technique with modern capillary gas chromatography (GC) and supercritical fluid chromatography (SFC). We used 3 samples of urushiol from Rhus verniciflua, one of Japanese, one of Chinese origin and one processed sample.

\section{EXPERIMENTAL}

Three samples of Japanese lacquer were obtained from the Tsutsumi Asakichi Urushi Co. Ltd., 600 Ainomachi Matsubara Agaru, Shimogyo-ku, Kyoto 600, Japan:

1) Japanese Raw Urushi (Ki-urushi) which was a moist orange-tan semi-solid and, when dissolved in dichloromethane, gave a clear yellowish-gold liquid-which we call in the context of this paper-A.

2) Japanese "Transparent" (Suki-urushi) which was a very dark brown viscous liquid and, when dissolved in dichloromethane, gave a cloudy orange-brown liquid, which we call B.

3) Chinese (Black) Urushi (Kuro-urushi) 
which was a black viscous liquid and, when dissolved in dichloromethane, gave a cloudy purple-black solution, which we call C.

The urushi samples were analyzed within one month after they were received. They had been kept in the tube in which they were received and stored in a desiccator under a nitrogen atmosphere and in a refrigerator. The samples had been obtained in $20 \mathrm{~g}$ quantities from the Urushi Co. sealed in tooth paste like tubes. The "completely filled" tubes were brought by one of the authors (OV) directly from Japan. The sample tubes had not been opened prior to the analyses.

Capillary GC analyses were carried out on a Hewlett Packard 5890 gas chromatograph. The column was a $25 \mathrm{~m} \times 0.2 \mathrm{~mm}$ i.d. fused silica column with HP-5 (SE-54, a phenylmethyl silicone) as stationary phase which allowed a maximum temperature of operation of $350^{\circ} \mathrm{C}$. Helium was used as the carrier gas at 25 psi and flame ionization was used for the detection of the compounds. The injection temperature was $300^{\circ} \mathrm{C}$ and the samples were run at a constant temperature increase of $5^{\circ} \mathrm{C}$ per minute starting from $220^{\circ} \mathrm{C}$ to $300^{\circ} \mathrm{C}$. The reproducibility between injections was better than $\pm 2 \%$. It is well known that different compounds have different responses to the detector (FID), and consequently the quantification of our analysis had its limitations. But the fact that the compounds which we analyzed are very similar in structure, probably allows the analysis to be judged as nearly quantitative. In order to get ultimate resolution the technique of "split injection" (40:1) was used. It has a drawback in that different compounds were not necessarily placed on the column with equal efficiency.

Supercritical fluid chromatography (SFC) was also used to analyze the urushi components. Conditions: 100 atm per 5 minutes to $416 \mathrm{~atm}$ at $10 \mathrm{~atm}$ per minutes. FID: $325^{\circ} \mathrm{C}$. Column: SB-30, 30\% biphenyl, 70\% Methyl Silicone.

${ }^{1} \mathrm{H}$ NMR spectra of the three urushi samples were determined in deuterated chloroform at $35^{\circ} \mathrm{C}$ on a JNM GX-500 spectrometer. Samples were handled under nitrogen atmosphere and the insoluble part of the samples (for Ki-urushi, $74 \%$; for Suki-urushi, $0 \%$, and for Kurourushi, $23 \%$ ) were removed by filtration prior to the NMR measurements.

\section{RESULTS AND DISCUSSION}

We have analyzed three samples of "urushi" using a combination of analytical techniques that we think are unique and useful for the identification of the components of the organic part of urushi. In this work we were not interested in the plant gums or in the glycoproteins nor were we interested in the amount or the function of laccase or other enzymes that are present in the sap of Rhus verniciflua.

The three samples of urushi were subjected to the following types of analyses: capillary gas chromatography (C-GC), supercritical fluid chromatography (SFC), potassium ionization of desorbed species ( $\mathrm{K}^{+}$IDS) and gas chromatography followed by electron impact mass spectrometry. The results of the C-GC and the $\mathrm{K}^{+}$IDS are shown in Table I. The peaks assignments for the capillary GC chromatograms are mentioned later.

In the past, the constituents of urushiol have been investigated by several research teams and individual components were isolated and characterized $^{14,15}$ by classical means. In recent years, HPLC and high resolution capillary GC have also been used to advantage for the analysis of urushiol. Several new constituents of urushiol have been isolated and identified. ${ }^{16-22}$ Analysis and separation have not only been carried out on genuine urushi, but the phenolic components of natural urushi have also been methylated or acetylated. The derivatized mixtures were then analyzed. ${ }^{19,21}$

It has been claimed, and probably properly so, that the quality of the raw urushi suitable for its use as lacquer depended mainly on the 
Table I. Constituents of the sap of samples of Rhus verniciflua

\begin{tabular}{|c|c|c|c|c|c|c|c|}
\hline \multirow[b]{2}{*}{ [M] } & \multirow[b]{2}{*}[\mathrm{M}]{$\mathrm{K}^{+}$} & \multicolumn{2}{|c|}{$\begin{array}{c}\text { Raw } \\
\text { Japanese raw-urushi } \\
\text { "Ki-urushi" } \\
\text { A }\end{array}$} & \multicolumn{2}{|c|}{$\begin{array}{l}\text { Transparent } \\
\text { Japanese } \\
\text { "Suki-urushi" } \\
\text { "transparent" } \\
\text { B }\end{array}$} & \multicolumn{2}{|c|}{$\begin{array}{c}\text { Black } \\
\text { Chinese urushi } \\
\text { (black) } \\
\text { "Kuro-urushi" } \\
\text { C }\end{array}$} \\
\hline & & $\begin{array}{l}\text { Retention } \\
\text { Time/min }\end{array}$ & $\%$ & $\begin{array}{l}\text { Retention } \\
\text { Time/min }\end{array}$ & $\%$ & $\begin{array}{l}\text { Retention } \\
\text { Time/min }\end{array}$ & $\%$ \\
\hline & & 9.42 & 5.7 & 9.44 & 3.4 & 9.43 & 3.9 \\
\hline & & $x$ & & 9.97 & 0.8 & 9.97 & 1.1 \\
\hline & & 10.33 & 3.8 & & & 10.34 & 1.6 \\
\hline \multirow[t]{2}{*}{318} & 357 & 11.23 & 22.1 & 11.27 & 32.5 & 11.25 & 27.9 \\
\hline & & $\begin{array}{c}11.45 \\
\text { sh }\end{array}$ & 3.2 & 11.46 & 4.0 & 11.46 & $\begin{array}{l}2.0 \\
\mathrm{sh}\end{array}$ \\
\hline \multirow[t]{4}{*}{314} & 353 & 12.21 & 62.5 & 12.27 & 58.2 & 12.24 & 60.5 \\
\hline & & 13.20 & 2.5 & 13.21 & 1.0 & $x$ & \\
\hline & & & & & & $x$ & \\
\hline & & & & & & 15.06 & 2.7 \\
\hline
\end{tabular}

amount of the urushiol triene component and the amount and the activity of the oxidation enzyme laccase. ${ }^{16}$

The catechol component of urushiol has a linear hydrocarbon side chain in the 3-position of the benzene ring. The double bonds of the unsaturated portion of the molecule are separated from the benzene ring of the catechol by 7 methylene groups. The diene and triene components have one methylene group in the 10 position of the aliphatic side chain between two olefinic linkages. Because of the location of the double bonds and the methylene linkages between the double bonds, these dienes and trienes are very susceptible to air oxidition in the presence of "oxidation catalysts" present in the sap of the Japanese lacquer tree. ${ }^{17,18}$ The enzyme laccase is known to initiate the oxidative polymerization of the unsaturated urushiol components. The chemical structure of these compounds is very similar to the compounds that are responsible for the oxidative polymerization of the unsaturated compounds of "drying oils" such as linseed oil or tung oil. In the case of urushi curing, the oxidation which leads to the "oriental lacquer product", requires also exposure to high humidity $(65-80 \%$ relative humidity, and even darkness is recommended).

Sample A was analyzed by several techniques and gave the following results (Figure 1A): C-GC showed peaks at the retention times 9.4 minutes and 9.9 minutes (small), 11.2 minutes and 12.2 minutes (large) and 11.4 minutes and 13.2 minutes (small). Several very small peaks with longer retention times were also noticeable.

The $\mathrm{K}^{+}$IDS analysis of A (Figure 2A) showed a strong mass peak $[\mathrm{M}] \mathrm{K}^{+}$at 353 daltons, with smaller peaks at $[\mathrm{M}] \mathrm{K}^{+}=355$ daltons and $[\mathrm{M}] \mathrm{K}^{+}=357$ daltons. There are also peaks at $[\mathrm{M}] \mathrm{K}^{+}=371$ daltons and $[\mathrm{M}] \mathrm{K}^{+}=373$ daltons. These two peaks were found to be due to the components hydrated on the double bond as mentioned later. Some smaller peaks at $[\mathrm{M}] \mathrm{K}^{+}=379$ daltons and $[\mathrm{M}] \mathrm{K}^{+}=395$ daltons are also discernible. The peaks at $[\mathrm{M}] \mathrm{K}^{+}=354$ daltons, 356 daltons, and 372 daltons seem to be isotope satellite peaks.

The $\mathrm{K}^{+}$IDS mass spectrum of the "dimer fraction" of A is shown in Figure 2B. It shows 


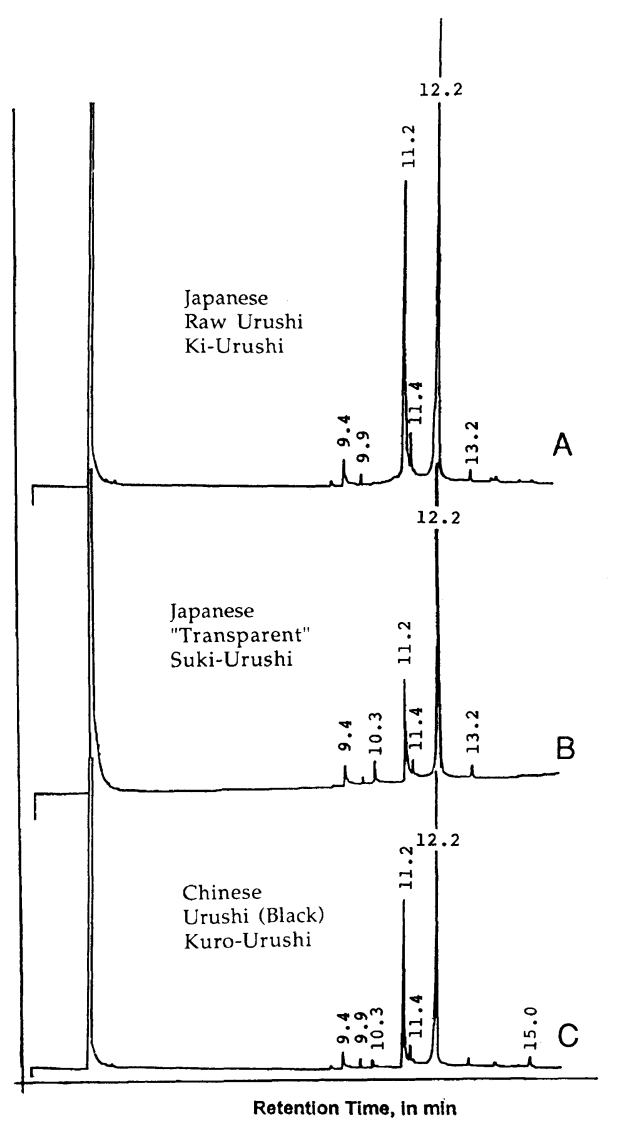

Figure 1. Capillary Gas chromatograms of three samples of the Sap of Rhus verniciflua. A, Japanese raw urushi (Ki-urushi); B, Japanese "transparent" (Suki-urushi); C, Chinese (black) urishi (Kuro-urushi).

the major peak of $[\mathrm{M}] \mathrm{K}^{+}=665$ daltons which accounts for the dimer of $[\mathrm{M}]^{+}=314$ daltons; 314 times two, plus the mass of $\mathrm{K}^{+}=39$ is 667 daltons, minus two hydrogen, which are lost by the oxidative dimerization of the phenolic portion of the molecule. Other "dimerization" and "cross-dimerization" products could also be seen in the mass region of $[\mathrm{M}] \mathrm{K}^{+}$of 660 to 672 daltons.

SFC of sample A showed two sets of peaks (Figure 3A). The first group has two well resolved major peaks at retention times of 28.0 minutes and 29.7 minutes, and two minor peaks at 26.1 minutes and at 30.1 minutes. The second group of the "dimer" peaks has a smaller,

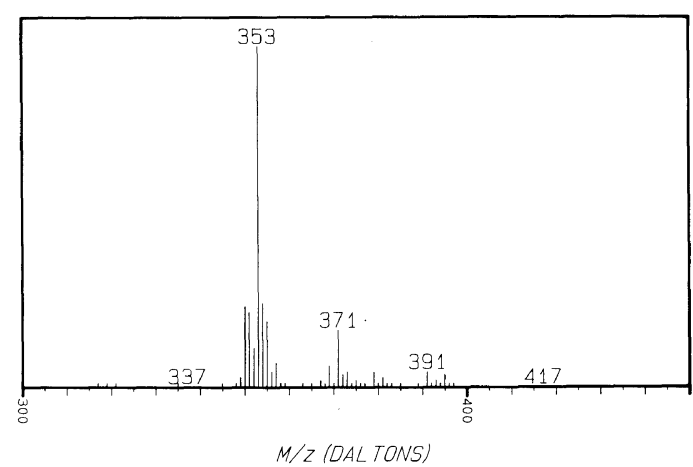

Figure 2A. Potassium ionization of desorbed species mass spectrum of Japanese "transparent" (Suki-urushi), monomer fraction.

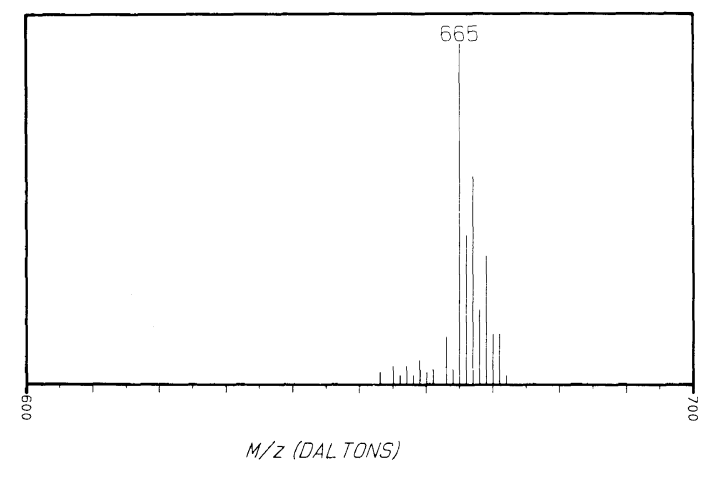

Figure 2B. Potassium ionization of desorbed species mass spectrum of Japanese "transparent" (Suki-urushi), dimer fraction.

broad and not well resolved peak centered at a retention time of 36.0 minutes.

The analysis of $\mathrm{B}$ gave the following results: C-GC showed peaks at the retention times of 9.4 minutes, 9.9 minutes (small), and a slightly larger peak at 10.3 minutes; additional peaks are at 11.2 minutes and 12.2 minutes (large) and at 11.4 minutes and 13.2 minutes (small) [Figure 1B].

$\mathrm{K}^{+}$IDS Analysis of B (Figure 4A) showed a strong mass peak $[\mathrm{M}] \mathrm{K}^{+}=353$ daltons (the $\mathrm{C}_{15}$ triene fraction), with smaller ones at $[\mathrm{M}] \mathrm{K}^{+}=355$ daltons (the $\mathrm{C}_{15}$ diene fraction) and $[\mathrm{M}] \mathrm{K}^{+}=357$ daltons, (the $\mathrm{C}_{15}$ monoene). There are also small peaks at $[\mathrm{M}] \mathrm{K}^{+}=371$ daltons and $[\mathrm{M}] \mathrm{K}^{+}=373$ daltons. Some 


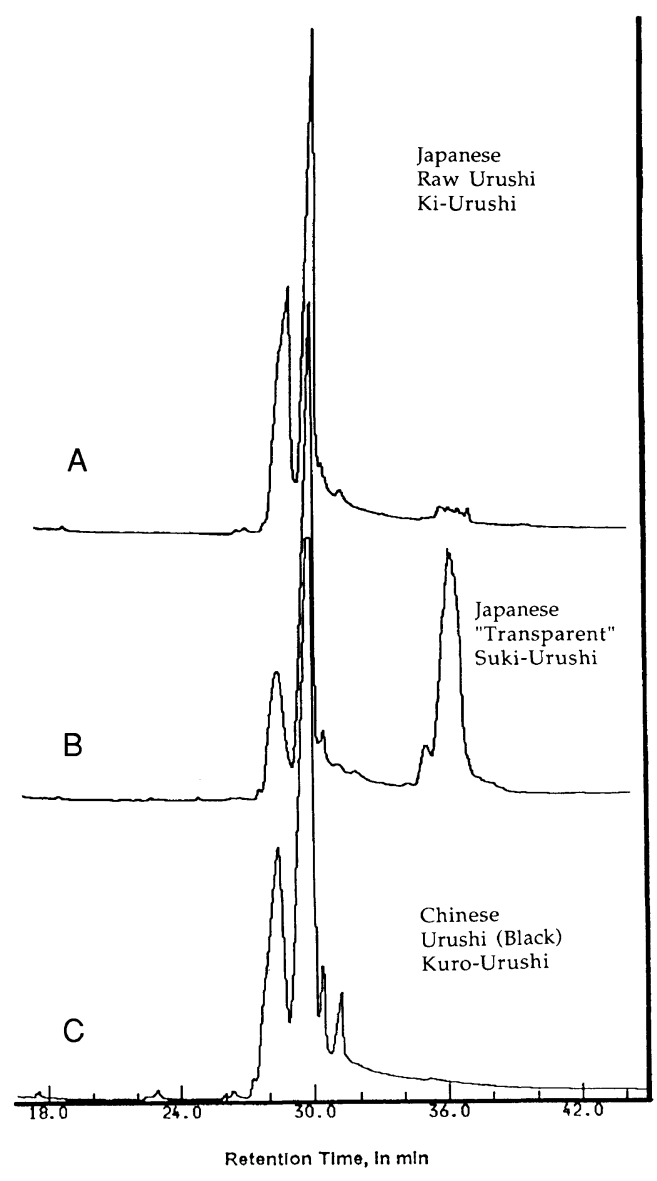

Figure 3. Supercritical fluid chromatograms of three samples of the sap of Rhus verniciflua. A, Japanese raw urushi (Ki-urushi); B, Japanese "transparent" (Sukiurushi); C, Chinese (black) urushi (Kuro-urushi).

smaller peaks at $[\mathrm{M}] \mathrm{K}^{+}=379$ daltons and $[\mathrm{M}] \mathrm{K}^{+}=395$ daltons are also discernible. The "dimer" fraction (Figure 4B) shows the main peak at $[\mathrm{M}] \mathrm{K}^{+}=659$ daltons, with over ten additional mass peaks, representing probably "cross-dimerization" peaks and isotope peaks.

SFC of B (Figure 3B) showed two groups of peaks. The first group has two well-resolved major peaks at a retention time of 28.0 minutes and 29.7 minutes, and perhaps as many as three minor peaks at retention times of 30.1 minutes, 30.6 minutes, and 31.7 minutes. In the second group, which seems to be the "dimer" fraction, we see a smaller peak at a retntion time of 35.0

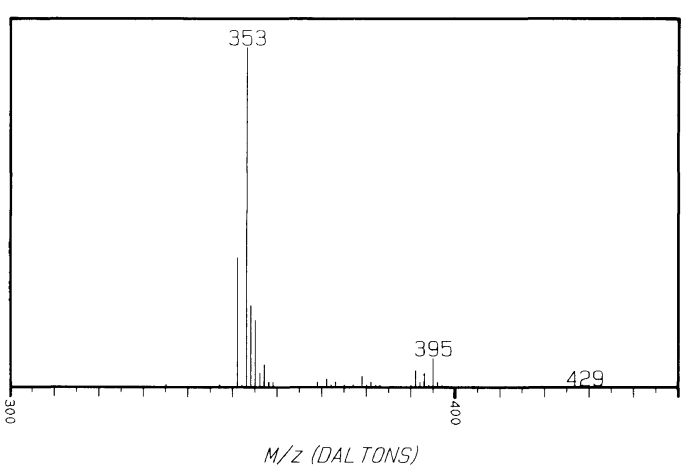

Figure 4A. Potassium ionization of desorbed species mass spectrum of Japanese raw urushi (Ki-urushi), monomer fraction.

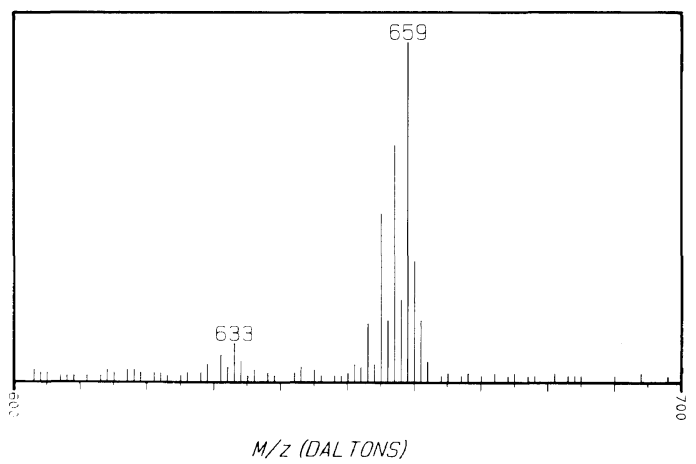

Figure 4B. Potassium ionization of desorbed species mass spectrum of Japanese raw urushi (Ki-urushi), dimer fraction.

minutes and the major peak at the retention time of 36.0 minutes. It is known that during the "sugurome" process about $20 \%$ of urushiol is converted to dimers and higher oligomeric substances. $^{22}$

Analysis of $\mathrm{C}$ gave the following results: C-GC [Figure 1C] showed peaks at the retention times of 9.4 minutes, 9.9 minutes (small), and at 10.3 minutes; additional peaks are also found at 11.2 minutes, 12.2 minutes (large), and at 11.4 minutes, 13.2 minutes, 14.0 minutes, and 15.6 minutes (small).

The $\mathrm{K}^{+}$IDS analysis of $\mathrm{C}$ [Figure 5] showed a strong mass peak $[\mathrm{M}] \mathrm{K}^{+}=353$ daltons, with smaller ones at $[\mathrm{M}] \mathrm{K}^{+}=355$ daltons and $[\mathrm{M}] \mathrm{K}^{+}=357$ daltons. In this mass spectrum, 


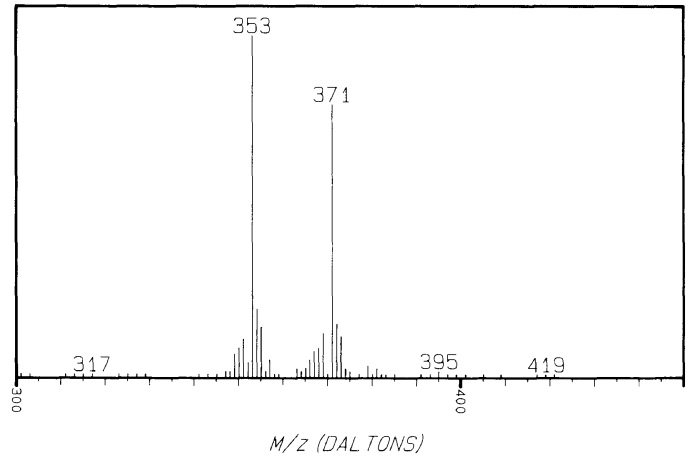

Figure 5. Potassium ionization of desorbed species mass spectrum Chinese (black) urushi (Kuro-urushi), monomer fraction.

the peak at $[\mathrm{M}] \mathrm{K}^{+}=371$ daltons is very large, with smaller peaks at $[\mathrm{M}] \mathrm{K}^{+}=373$ daltons and $[\mathrm{M}] \mathrm{K}^{+}=375$ daltons. Some smaller peaks at $[\mathrm{M}] \mathrm{K}^{+}=379$ daltons, $[\mathrm{M}] \mathrm{K}^{+}=381$ daltons, and $[\mathrm{M}] \mathrm{K}^{+}=395$ daltons are also discernible. The peaks between $[\mathrm{M}] \mathrm{K}^{+}$of 370 to 375 seem to come from water addition to the original $\mathrm{C}_{15}$ triene, possibly even diene or monoene component during storage after harvesting of the sap or even before the sap is harvested.

The component with $[\mathrm{M}]^{+}=332,\left([\mathrm{M}] \mathrm{K}^{+}\right.$ =371) was isolated by HPLC and the structure was determined by ${ }^{1} \mathrm{H}$ NMR spectroscopy as shown below.

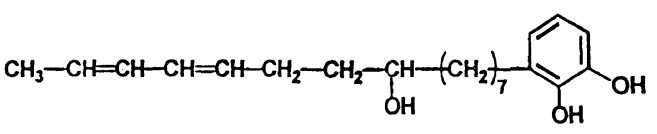

Details of the analysis will be reported in a separate article. ${ }^{23}$

In the mass spectrum of $\mathrm{C}$, the masses of $[\mathrm{M}] \mathrm{K}^{+}$up to 750 daltons have been recorded (not shown in the Figure because of its similarity to Figure $2 \mathrm{~B}$. Of the peaks higher than $[\mathrm{M}] \mathrm{K}^{+}=600$ daltons, the first group has the major peak at $[\mathrm{M}] \mathrm{K}^{+}=665$ daltons accompanied with peaks at $[\mathrm{M}] \mathrm{K}^{+}=667$ daltons, $[\mathrm{M}] \mathrm{K}^{+}=669$ daltons, and 671 daltons; two smaller peaks are at $[\mathrm{M}] \mathrm{K}^{+}=683$ daltons and $[\mathrm{M}] \mathrm{K}^{+}=685$ daltons.

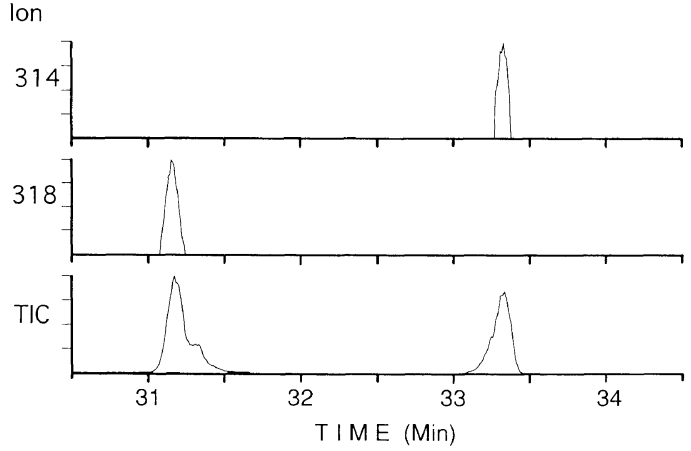

Figure 6. GC of Japanese Suki-urushi.

No higher mass peaks have been found in the $\mathrm{K}^{+}$IDS mass spectra of $\mathrm{A}, \mathrm{B}$, and $\mathrm{C}$, which could indicate higher oligomers of the urushiols.

The SFC analysis of $\mathrm{C}$ (Figure 3C) showed only one group of peaks. There are two well resolved major peaks at retention times of 28.0 minutes and 29.7 minutes, and two minor peaks at retention times of 23.0 minutes and 26.2 minutes. Two additional, reasonably well resolved peaks could be seen at retention times of 30.1 minutes and 30.6 minutes. The dimer fraction in this sample seems to be very small.

Based on our C-GC results the most abundant peaks in each of the three samples of urushi that we analyzed are the two with retention times of 11.2 minutes (about 30\%) and 12.2 minutes (about 60\%), respectively. These data are quite constant regardless of three samples that we analyzed. Comparing these data with the $\mathrm{K}^{+}$IDS results, the 11.2 minute peak seems to coincide with the 28.0 minute peak of the SFC spectrum.

The C-GC analysis of A was now repeated by a somewhat different technique that allowed the individual peaks to be immediately analyzed by regular electron impact mass spectrometry (Figure 6). The spectrum of A shows two major peaks, one at a retention time of 31.2 minutes, which could consist of more than one compound (isomers) and another peak at a retention time of 33.3 minutes, which could consists of at least two compounds 


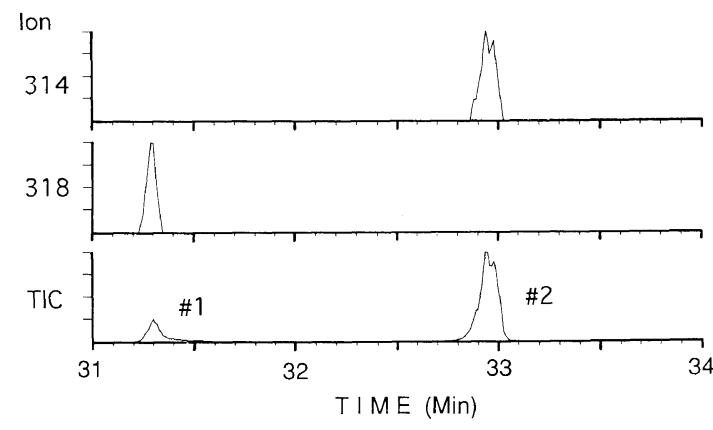

Figure 7. GC of Japanese raw urushi, Ki-urushi.

(structural and stereoisomers). The first peak was identified as a compound with a $[\mathrm{M}]^{+}=318$ which would account for the $\mathrm{C}_{15}$ monoene fraction, and the second peak with a $[\mathrm{M}]^{+}=314$ which would account for the $C_{15}$ triene fraction.

The mass peaks by the CG mass spectrometry technique of electron impact have a [M] in daltons, not the $[\mathrm{M}] \mathrm{K}^{+}$which are obtained by $\mathrm{K}^{+}$IDS mass spectrometery and are 39 daltons or the mass of $\mathrm{K}^{+}$less than $[\mathrm{M}] \mathrm{K}^{+}=353$ daltons. Indeed, the mass peaks obtained by electron impact spectrometry showed a $[\mathrm{M}]^{+}=314$ for the triene and $[\mathrm{M}]^{+}=318$ for the monoene. The monoene was the peak that eluted first in the C-GC followed by the triene. The triene $[\mathrm{M}]^{+}=314$ was actually a composite of at least three compounds. These are undoubtedly cis and trans isomers of the $8,11,14$ trienes but also of some structural isomers with three double bonds. In the past several of these isomers have been identified and characterized.

GC followed by electron impact mass spectrometry was also carried out on a sample of B (Figure 7). It showed the same characteristics as $\mathrm{A}$ with peaks of $[\mathrm{M}]^{+}=318$ daltons and $[\mathrm{M}]^{+}=314$ daltons. The electron impact spectrum of peak $\# 1$ is shown in Figure $8 \mathrm{~A}$, and that of peak $\mathrm{B}$ in Figure $8 \mathrm{~B}$.

The GC spectrum of $C$ prior to its analysis for electron impact is shown in Figure 9.

${ }^{1} \mathrm{H}$ NMR analysis of the three Urushi samples on a $500 \mathrm{MHz}{ }^{1} \mathrm{H}$ NMR spectrometer

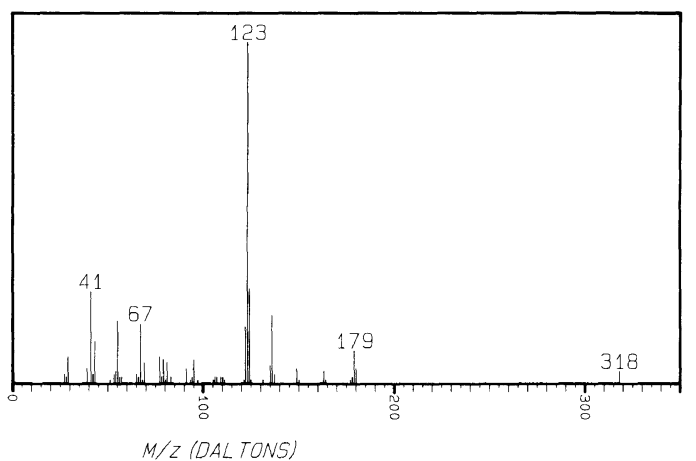

(A)

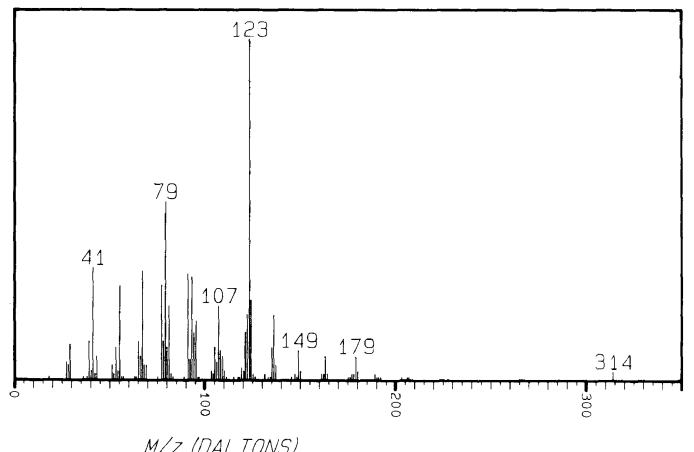

(B)

Figure 8. Electron impact mass spectrum of Japanese raw urushi, Ki-urushi. A, Peak $\# 1 ;[\mathrm{M}]^{+}=318$ Daltons. B, Peak $\sharp 2 ;[\mathrm{M}]^{+}=314$ Daltons. (see Figure 7)

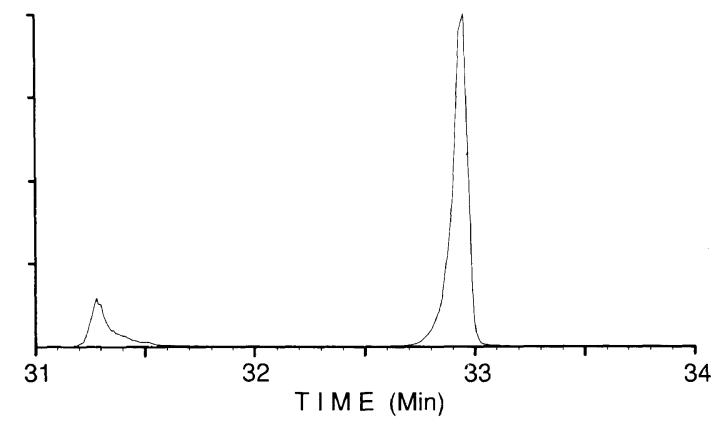

Figure 9. GC of Chinese (black) urushi, Kuro-urushi.

are shown in Figures 10A, 10B, and 10C, respectively. Most of the signals were commonly observed in all the spectra, although the intensity ratios were different from each other due to the different compositions.

Significant differences were observed in the 

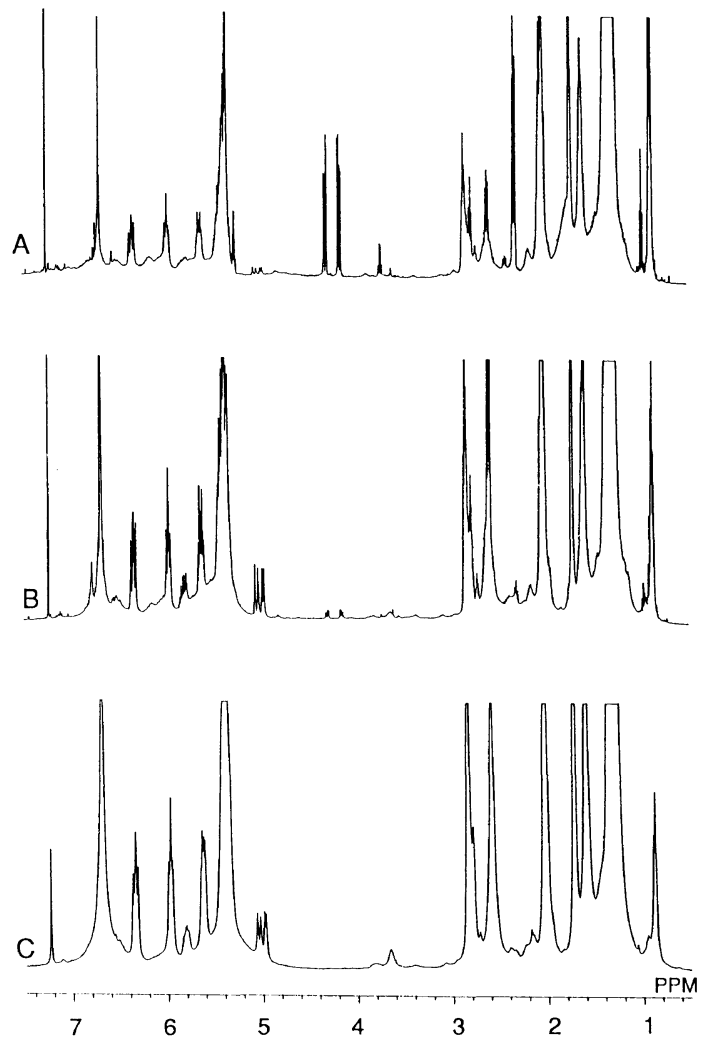

Figure 10. ${ }^{1} \mathrm{H}$ NMR spectra of urushi samples measured in deuterated chloroform at $35^{\circ} \mathrm{C}$ at $50 \mathrm{GHz}$. A, Ki-urushi; B, Suki-urushi; C, Kuro-urushi.

chemical shift range between 3.5 and $4.4 \mathrm{ppm}$. Though the signals seen in this range were not assigned in the present study, a pair of sharp double-doublets at 4.15 and $4.29 \mathrm{ppm}$ could most likely be assigned to methylene protons adjacent to an oxygen atom; $-\mathrm{CH}_{2} \mathrm{O}$ - .

The chemical structure of Suki-urushi was analyzed in detail by ${ }^{1} \mathrm{H}$ COSY (Figure 11). The chemical shift peak at $6.69 \mathrm{ppm}$ which had no correlation peak with other signals could be assigned to phenyl protons. The strong signal at $1.32 \mathrm{ppm}$ was assigned to methylene protons of the alkylene chain from its chemical shift value. The olefinic proton signals were observed between 5 and $6.4 \mathrm{ppm}$, some of which (a, b, c, d, f, g, and $b^{\prime}$ ) showed correlation peaks with aliphatic proton signals $\left(e, c^{\prime}, h, t\right)$. Signal e at $2.84 \mathrm{ppm}$ showed correlation peaks with two different olefinic proton signals $d$ (5.63 ppm) and $\mathrm{f}(5.39 \mathrm{ppm})$, which exhibit a correlation peak with each other. Thus the signal e could be assigned to the protons of the methylene group;

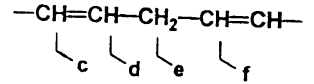

The signal $d$ showed a correlation peak with an olefinic proton c $(6.34 \mathrm{ppm})$ which had a small correlation peak with signals e due to $4 J$ coupling. Further connectivity of the correlation could be followed as $\mathrm{c}-\mathrm{b}(5.96 \mathrm{ppm})-\mathrm{a}$ $(5.63 \mathrm{ppm})$. The signals a and b correlated with the signal $\mathrm{t}(1.72 \mathrm{ppm})$, which had no other correlation and is assigned to the terminal methyl protons. Thus, a component of urushiol exists, which has a partial structure of a triene at the end of the molecule as shown below.

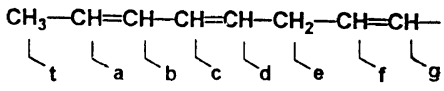

The signal g, which overlapped with signal a, showed a correlation peak with signal $h$ $(2.03 \mathrm{ppm})$, which correlated with a strong signal $i(1.32 \mathrm{ppm})$ and is related to the methylene protons in the alkylene chain. Thus signal $\mathrm{h}$ was assigned to the allylic methylene protons $=\mathrm{CH}-\mathrm{CH}_{2}-\mathrm{CH}_{2}-$.

A similar analysis of correlation in the COSY spectrum starting from a shoulder signal $\mathrm{c}^{\prime}$ at $2.83 \mathrm{ppm}$, which correlated with olefinic proton signals, indicated a connectivity of signals as follows: $\mathrm{c}^{\prime}-\mathrm{b}^{\prime}(5.8 \mathrm{ppm})-\mathrm{a}^{\prime}(5.0 \mathrm{ppm})$.

The signal $a^{\prime}$ did not correlate with other proton signals and thus could be assigned to terminal vinyl methylene protons. The signal $\mathrm{c}^{\prime}$ also correlated with olefinic proton signals that overlapped with strong peaks at $5.39 \mathrm{ppm}$, but did not with aliphatic proton signals. The result and the chemical shift of $c^{\prime}$ suggested the following end group structure for one of the minor components;

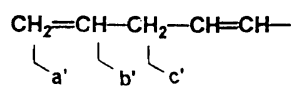



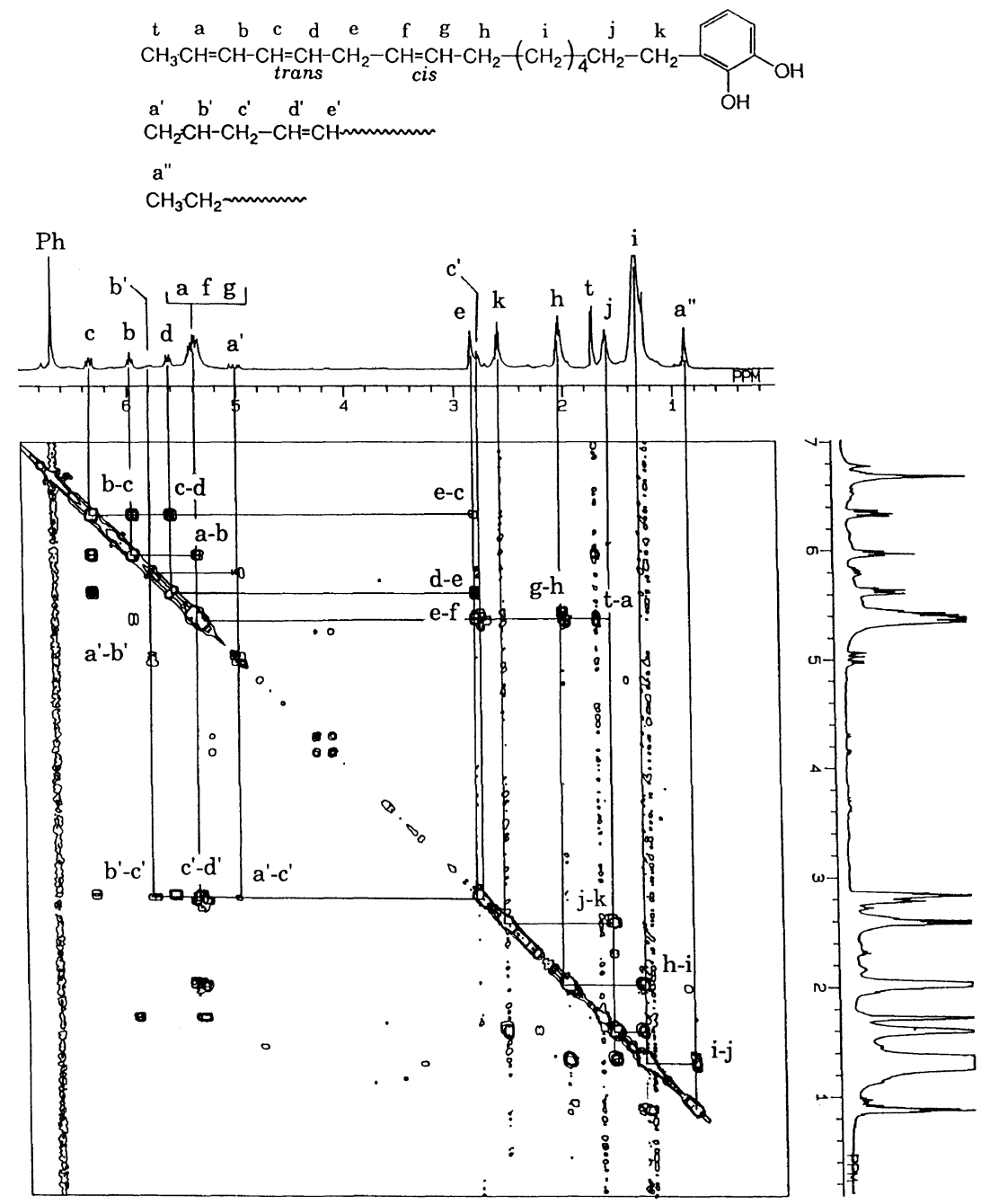

Figure 11. ${ }^{1} \mathrm{H}$ COSY spectrum of Suki-urushi measured in deuterated chloroform at $35^{\circ} \mathrm{C}$ at $500 \mathrm{MHz}$.

Table II. Relative amounts of three types of end structure of Urushi

\begin{tabular}{llrrr} 
& & & \multicolumn{2}{c}{ Relative amount $/ \%$} \\
\cline { 3 - 4 } End group structure & Ki-urushi & Suki-urushi & Chinese urushi \\
\hline 1 & $\mathrm{C}_{3} \mathrm{CH}=\mathrm{CH}-\mathrm{CH}=\mathrm{CH}-\mathrm{CH}_{2}-\mathrm{CH}=\mathrm{CH}-$ & 45 & 52 & 58 \\
2 & $\underline{\mathrm{H}}_{2}=\mathrm{CH}-\mathrm{CH}_{2}-\mathrm{CH}=\mathrm{CH}-$ & 3 & 14 & 15 \\
3 & $\underline{\mathrm{C}}_{3}-\mathrm{CH}_{2}$ & 52 & 33 & 27 \\
\hline
\end{tabular}

The methyl signal $\mathrm{a}^{\prime \prime}$ at $0.88 \mathrm{ppm}$ showed only one correlation peak with the methylene proton signal $i$ and was assigned to the terminal methyl group of the aliphatic chain.

The signal $\mathrm{k}$ can be assigned to the benzylic methylene protons. This judgement is based on 
its shift value of $2.59 \mathrm{ppm}$, which correlated with peak $\mathrm{j}$ at $1.60 \mathrm{ppm}$, which in turn showed a correlation peak with the methylene proton singal i.

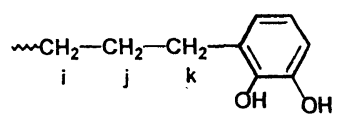

As mentioned above, at least three different types of end groups can be identified in the structural components of urushiol, the structures are shown in Table II. Although there are several unidentified signals, the relative abundances of the three types of end groups were accurately determined from the peak intensities of the underlined protons.

The structure of the major components that had end group 1 could be drawn as shown below. The coupling constants between the olefinic protons, as determined from $1 \mathrm{D}$ and 2D $J$ resolved ${ }^{1} \mathrm{H}$ NMR, revealed the geometric isomerism at double bonds as follows.

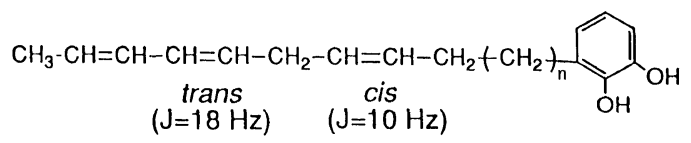

The compound with the molecular weight $314\left([\mathrm{M}] \mathrm{K}^{+}=353\right.$ which was observed by $\mathrm{K}^{+}$IDS mass spectrometry as the major component of the urushiol mixture, was consistent with the structure with $n=6 \quad\left(\mathrm{C}_{15}\right.$ triene structure). The component with the saturated end groups 3 may have one more double bond in the chain.

\section{CONCLUSION}

We conclude that the combination of ${ }^{1} \mathrm{H}$ NMR spectroscopy and $\mathrm{K}^{+}$IDS spectrometry revealed at least the following points.

1) The triene structure with an end group 1 is included in the $\mathrm{C}_{15}$ side chain of the molecule.

2) The $\mathrm{C}_{15}$ component with a vinyl end group is a component of urushi.
3) The $\mathrm{C}_{15}$ component with the saturated end group 3 may be a monoene.

In the past, the compound with the triene end group 1 has been separated from the sap of the lacquer tree Rhus verniciflua and analyzed by $400 \mathrm{MHz}{ }^{1} \mathrm{H}$ NMR spectroscopy. ${ }^{20}$ The ${ }^{1} \mathrm{H}$ NMR and the ${ }^{13} \mathrm{C}$ NMR assignments of the acetate derivative of this compound was also carried out previously by 2D NMR spectroscopy. ${ }^{24}$ The present analysis of the mixture was consistent with these assignments. The other two compounds with the end groups 2 and 3 have not been characterized by NMR, although the existence of them has been speculated.

Acknowledgments. This work was inspired by the Pacific Polymer Federations series of Symposia sessions on "Polymer Science and the Arts". The help and patience in explaining the fine points of the Oriental Lacquer by Mr. Shigeru Tsutsumi, President Tsutsumi Asakichi Urushi Co., Ltd., is greatly appreciated. We had also a great deal of help in the understanding of Japanese lacquer and its application for the design and preparation of superior art objects from members of the staff of the H. Nishimura Lacquerware Co., Ltd. on Zohiko Urushi Art, Raisen Dori, Okasaki Park, Kyoto, Japan. We are greatly indebted to Ju Kumanotani, Professor Emeritus, The University of Tokyo, for making us acquainted with the literature of oriental lacquers and with many most pleasant discussions on the "urushi problem" and to John D. Mitchell, chief scientist of The New York Botanical Garden, for his advice on the botany of the Poisonous Anacardiaceae Genera species.

\section{REFERENCES}

1. E. Matsui, "The Chemistry of Lacquers," Daily Industry Newspaper Inc., Tokyo, 1963.

2. "The New Encyclopedia Britannica," Vol. 10, 15th ed, Chicago, 1984, p 575.

3. J. C. Y. Watt and B. B. Ford, in "East Asian Lacquer, J. P. O. Neill, Ed., The Metropolitan Museum of Art, 
New York, 1992.

4. Beatrix Von Rague, "A History of Japanese Lacquerwork," University of Toronto Press, Toronto and Buffalo, 1976.

5. Y. M. Du, in "Urushi," N. S. Bromelle and P. Smith, Ed., The Getty Conservation Institute, Marina del Rey, CA, 1985.

6. Carl R. Noller, "Chemistry of Organic Compounds," 3rd ed., W. B. Saunders Co., Philadelphia and London, 1966, p 562.

7. T. Kato and J. Kumanotani, J. Polym. Sci., A-1, 1455 (1969).

8. T. Kato, Y. Yokoo, T. Taniai, and J. Kumanotani, Can. J. Chem., 47, 2106 (1969).

9. T. Kato and J. Kumanotani, Bull. Chem. Soc., Jpn., 42, 2378 (1969).

10. J. Kumanotani, Makromol. Chem., 179, 47 (1979).

11. M. A. Elsohly, P. D. Adawadkar, C. Y. Ma, and C. E. Turner, J. Natl. Prod., 45, 532 (1982).

12. J. Kumanotani, T. Kato, and A. Hikosaka, J. Polym. Sci., C, 23, 519 (1969).

13. R. Oshima, Y. Yamauchi, C. Watanabe, and J. Kumanotani, J. Org. Chem., 50, 2621 (1985).
14. R. Majima, Chem. Ber., 55B, 172 (1922).

15. S. V. Suthankar and C. W. Dawson, J. Am. Chem. Soc., 76, 5070 (1954).

16. J. H. P. Tyman and A. J. Mathews, J. Chromatogr., 235, 149 (1982).

17. Y. Yamauchi, R. Oshima, and J. Kumanotani, J. Chromatogr., 198, 49 (1980).

18. Y. Yamauchi, T. Murakami, and J. Kumanotani, $J$. Chromatogr., 214, 343 (1981).

19. Y. Yamauchi, R. Oshima, and J. Kumanotani, J. Chromatogr., 243, 71 (1982).

20. Y. M. Du, R. Oshima, and J. Kumanotani, $J$. Chromatogr., 284, 463 (1984).

21. Y. M. Du, R. Oshima, H. Iwatsuki, and J. Kumanotani, J. Chromatogr., 295, 179 (1985).

22. R. Oshima, Y. Yamauchi, C. Watanabe, and J. Kumanotani, J. Org. Chem., 50, 2613 (1985).

23. K. Hatada, T. Kitayama, T. Nishiura, A. Nishimoto, W. J. Simonsick, Jr., and O. Vogl, Makromol. Chem., in press.

24. Z. G. Huang, F. Qiu, J. You, B. G. Qian, L. Y. Li, J. Q. Qiu, H. Z. Yuan, and L. F. Shen, Chem. J., Chinese Univ., 8, 187 (1987). 